\title{
Relationship between age, category and experience with the soccer referee's self-efficacy
}

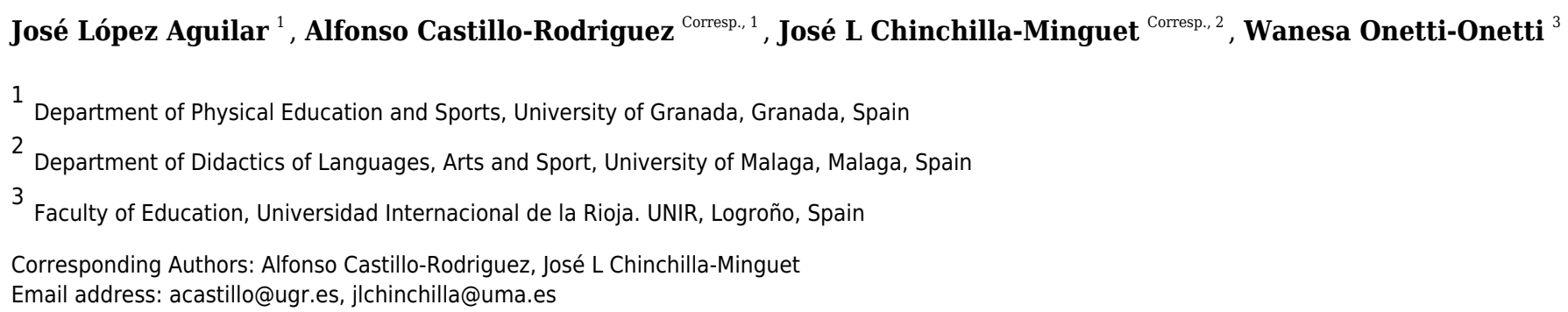

Soccer referees encounter stressful situations during competitions and sometimes even outside them, which may affect their decision making. Therefore, it is important that they possess or acquire optimal levels of self-efficacy, since it is related to less stress during competition, also guaranteeing sports performance and prevent sports abandonment. The objectives of this study were to characterize the profile, in terms of self-efficacy, of SRs depending on their category, age, and experience and to determine the relationship of these factors on SR self-efficacy. Two-hundred fifty-six Spanish referees participated in this study and Referee Self-Efficacy Scale was administered and completed. The results indicated that the SRs older than 25 years, of national category, and with experience greater than or equal to 8 years, have higher levels of self-efficacy than those with the least $(p<.01)$. Likewise, moderate positive correlations were also observed between global self-efficacy and the category, age, and experience of the SRs. In conclusion, age, category and experience factors relate the self-efficacy of the SR, which can explain up to $17 \%$ of the variance, affecting decision-making and other decisive behaviors in the competition. These findings are of interest to delegations and referee committees seeking to implement psychological intervention programs to prevent burnout and abandonment of sports practice due to the consequences of low self-efficacy. 


\section{Relationship between age, category and experience with the soccer referee's}

\section{2 self-efficacy}

3

4 Running head: Self-efficacy in soccer referee

6 José López-Aguilar¹, Alfonso Castillo-Rodríguez ${ }^{*}$, José Luis Chinchilla-Minguet² \&

7 Wanesa Onetti-Onetti ${ }^{3}$

$8{ }^{1}$ Department of Physical Education and Sports. University of Granada, Granada, Spain.

92 Department of Didactics of Languages, Arts and Sports. University of Malaga, Malaga, Spain.

$10{ }^{3}$ UNIR. Universidad Internacional de la Rioja, Logroño, España.

$12 *$ Corresponding author:

13 Alfonso Castillo-Rodríguez

14 Faculty of Sport Sciences, University of Granada

15 Ctra.Alfacar s/n. 18011- Granada (Spain)

16 acastillo@ugr.es; +3495824 4377

17 Data availability statement: Available.

18 Funding statement: This study has been funded by the project PPJIA2020.04, of the

19 Precompetitive Research Projects program for Young Researchers of the Own Plan 2020, of the

20 University of Granada.

21 Conflict of interest disclosure: none

22 Ethics approval statement: This study was approved by the Ethics Committee of the University

23 of Granada, Spain (471/CEIH/2018). 
24 Permission to reproduce material from other sources: N/A. 


\section{Relationship between age, category and experience 26 with the soccer referee's self-efficacy}

\section{Abstract}

29 Soccer referees encounter stressful situations during competitions and sometimes even outside them, which may affect their decision making. Therefore, it is important that they possess or acquire optimal levels of self-efficacy, since it is related to less stress during competition, also guaranteeing sports performance and prevent sports abandonment. The objectives of this study were to characterize the profile, in terms of self-efficacy, of SRs depending on their category, age, and experience and to determine the relationship of these factors on SR self-efficacy. Twohundred fifty-six Spanish referees participated in this study and Referee Self-Efficacy Scale was administered and completed. The results indicated that the SRs older than 25 years, of national category, and with experience greater than or equal to 8 years, have higher levels of self-efficacy than those with the least $(p<.01)$. Likewise, moderate positive correlations were also observed between global self-efficacy and the category, age, and experience of the SRs. In conclusion, age, category and experience factors relate the self-efficacy of the SR, affecting decision-making and other decisive behaviors in the competition. These findings are of interest to delegations and referee committees seeking to implement psychological intervention programs to prevent burnout and abandonment of sports practice due to the consequences of low self-efficacy.

Keywords: Decision making, pressure, personality, competition, football, Referee Self-Efficacy Scale. 


\section{Introduction}

48 Sports referees and judges are essential in competition since they ensure that sports games is carried out safely and fairly with respect to the regulations of the sport in question (Warner et al., 2013). Although the referee has an indispensable role in the correct development of the indicated sporting discipline, refereeing has scarcely been studied by researchers (Guillén et al., 2019; Loghmani et al., 2018; Webb et al., 2016) . Referees must be attentive to all aspects of the game, evaluate situations, and make decisions in a timely manner (Schweizer et al., 2011). There are more than 5 million soccer referees (SRs) around the world (FIFA, 2004) making decisions and enforcing the rules of the game (Soriano et al., 2018) as well as paying attention to the behavior of soccer players (both on the field and on the bench) and technical staff (Castillo-Rodríguez et al., 2020). Proper decision making depends on multiple factors, such as, optimal physical condition for its category and having passed physical tests and theoretical tests established by the corresponding Referees Committee (Muñoz-Arjona \& Castillo-Rodríguez, 2020). The SR must be able to run distances similar to that of soccer players in their categories (Barros, 2007; Di Salvo, 2007) to have better positioning in the plays and therefore a clearer observation to make timely decisions. In addition, psychological skills such as concentration, self-confidence, selfefficacy, motivation (Castillo-Rodríguez et al., 2020), among others related to sports performance, are required that allow them to make judgments correctly or face erroneous decision-making due to the continuous stress of competition (Soriano et al., 2018) to achieve excellent refereeing (Giske et al., 2016; Weinberg \& Richardson, 1990). Today, the stress of competition is greater due to the social and economic impact that soccer has (Ramírez et al., 2006), since a decision can cause variations in the classification and consequently, the budget of said team to the following season. If this stress affects the SR during the competition, it could 
70 impact on the physiological level (González-Oya, 2006), e.g., increase in the minimum heart rate

71 at the beginning of the competition which may impair SR performance (Castillo-Rodríguez et al.,

72 2020) and alterations in motor and visual perception (Tornero-Aguilera \& Clemente-Suárez,

73 2018). These physiological changes could negatively affect judgment of a certain action in the

74 competition. For these reasons, the development of psychological skills becomes important if

75 they are practiced for a considerable time together with physical training (González-Oya \& Dosil,

76 2004; González-Oya \& Dosil, 2007; Guillén \& Feltz, 2011; Ramírez et al., 2006).

77 A psychological construct that has been shown to reduce stress and anxiety related to the

78 performance of a task or job is that of self-efficacy (Bandura 1997). The concept of self-efficacy

79 of a person includes optimistic beliefs in himself and it is defined as the strength of conviction of

80 a person to successfully perform a behavior required to achieve a certain result in a task

81 (Bandura, 1997). These perceptions are expected to influence the choice of tasks, effort made

82 and resistance to failure or better, resilience. Furthermore, it is known that self-efficacy allows

83 people to adapt effectively to new and changing situations (Callan, Terry, \& Schweitzer, 1994)

84 as would occur in the case of the SR or Sports judge. According to the theory of self-efficacy, it

85 influences stress and anxiety through beliefs about personal control of actions, thoughts and

86 affection (Bandura, 1997). Consequently, if the SRs have greater self-efficacy, they will have

87 greater self-confidence and will be able to handle the matches better since they will not have

88 high levels of stress impairing their performance during matches. It should be noted that

89 researchers have developed, based on Bandura (1997), different conceptual frameworks to

90 differentiate self-efficacy in different areas such as organizational (Stajkovic \& Luthans, 1998),

91 academic (Federici \& Skaalvik, 2012; Bong, 2001) and sports (Sullivan \& Kent, 2003). Within

92 the sports self-efficacy, there is the one related to the referee, which is called refraction for 
93 convenience. Highly effective referees must be more precise in their decisions, more effective in

94 their performance, more committed to their profession, have more respect from coaches,

95 administrators and other officials, and be able to avoid the stress that refereeing generates. In fact,

96 the aspect that most interests and worries referees is self-confidence, as some empirical studies

97 have confirmed (Guillén \& Jimenez, 2001; Guillén, 2003a).

98 In the last years, studies have been carried out on the construct of self-efficacy in different areas

99 such as academic or sports, in which we highlight studies with athletes and coaches. This is not

100 the case at the referee level because being one of the most worrying aspects, this field of

101 knowledge is scarcely studied by science (Ede, Hwang, \& Feltz, 2011). Within referee topic,

102 self-efficacy is the confidence or belief of successful decision-making by the referee (Guillén \&

103 Feltz, 2011). One way to validly and reliably measure self-efficacy in referees and sports judges

104 is through the REFS questionnaire (Referee Self-Efficacy Scale) developed and validated in its

105 original version by Myers et al. (2012) and in its Spanish version by Guillén et al. (2019). In

106 addition to providing a one-dimensional score, it also includes multidimensionality with 4

107 specifics in refereeing: game knowledge, which refers to the confidence that the SR has in the

108 knowledge of his or her sport/regulations; decision making refers to the SR's confidence and

109 ability to make decisions during the game; pressure refers to the SR's confidence in not being

110 influenced by the pressure of the encounter; and communication which is the referee's ability to

111 communicate effectively. We must emphasize and consider that the subscales of game

112 knowledge, decision making, communication, and preassure, which are considered psychological

113 abilities, are measured in the REFS questionnaire.

114 Regarding studies on self-efficacy in SR, little treatment has been observed in this field (Guillén

115 et al. 2019), hence there is a need to investigate self-efficacy in referees to determine its 
116 influence on sports performance. A study carried out on handball referees stands out (Diotaiuti et

117 al., 2017), it showed that referees of a higher category (national referees) had higher levels of

118 self-efficacy than referees of a lower category (regional referees). This category is also

119 recognized in science for the level of the referees, since they must pass some physical tests in

120 order to compete in higher categories (Muñoz-Arjona \& Castillo-Rodriguez, 2020). Similarly,

121 experience in refereeing is also influential in self-efficacy, since referees with less than 4 years of

122 experience had lower levels of self-efficacy than referees with more experience. However, no

123 differences were found for age in terms of confidence between other psychological abilities in

124 the study by Nazarudin et al. (2014) in rugby referees; this may be due to the high age of the

125 sample, as only $25 \%$ of the subjects were under 30 years of age. As mentioned before, the

126 higher-category SRs generally exhibit higher levels of self-efficacy (Diotaiuti et al., 2017),

127 enabling mitigation and reduction of stress during matches (Guillén, 2003b) and increased use of

128 mental training strategies at similar levels of physical training (Giske et al., 2016). However,

129 other studies reported a negative correlation between self-efficacy and stress (González-Oya \&

130 Dosil, 2004; Soriano et al., 2018), with the least experienced SRs facing the greatest stress in

131 competition. In addition, another study (Micoogullari et al., 2017) showed that SRs from Turkey

132 with more than 15 years of experience had greater stress control than those with less experience.

133 Regarding age and category, González-Oya and Dosil (2004) demonstrated that older SRs (over

13440 years old) have greater stress control than younger ones (less than 20 years old). In addition,

135 the SRs of the highest category obtained higher stress control scores, which could mean that the

136 SRs of older age and category have greater self-efficacy than those of the lower category. In

137 soccer, basketball and handball sports, the Turkish referee's self-efficacy is positively related to

138 age and experience (Karacam \& Adiguzel, 2019; Karacam \& Pulur, 2017), presenting variability 
139 depending on the type of sport, being in handball referees, the lowest scores (Karacam \& Pulur,

140 2017). However, it is unknown to date if these results would be the same in referees from other

141 countries, and therefore, who compete in other leagues with different cultures, such as Spain.

142 The contribution of the present study consists in demonstrating that the self-efficacy of the

143 Spanish SR increases according to the category (Hypothesis [H1a]), age (H1b) and experience

144 (H1c), and therefore, could be determining factors for the SR to be able to rise in category,

145 through linear regressions $(\mathrm{H} 2)$. Likewise, the aims of this study were to characterize the self-

146 efficacy of SRs depending on their category, age, and experience, and to establish relationships

147 of these factors in order to finally establish predictive equations of perceived self-efficacy. In this

148 way, the importance of the study resides in better understanding the psychological profile of SR

149 in order to prevent anxiety and stress states derived from low self-efficacy.

150 Method

\section{Participants}

152 Two-hundred fifty-six male amateur SRs belonging to the Andalusia Committee of Soccer

153 Referees voluntarily participated in the present study. The sampling was of the non-probabilistic

154 type from the Andalusia SR population. After contacting the Andalusia Committee, they

155 communicated it to the SR. The inclusion criteria were that the referees had passed the

156 corresponding relevant physical and theoretical tests of the season and that they had not had

157 injuries in the last 6 months that would have prevented them from carrying out their refereeing

158 work. Of these two-hundred fifty-six amateur SRs, 72 belong to national category (highest

159 category), 50 SRs of Honor Division or State category, 78 SRs of Provincial category, and 56 are

160 SRs of Base category (lowest category). The ages of the SRs were between 18 and 34 years old;

161 the weight between 51 and $105 \mathrm{~kg}$; height between 160 and $191 \mathrm{~cm}$; and experience from 1 to 16 
162 seasons in refereeing. The mean age, weight, height, and experience in refereeing were $23.7 \pm$

1633.4 years, $72.7 \pm 8.9 \mathrm{~kg}, 177.5 \pm 8.9 \mathrm{~cm}$, and $6.45 \pm 3.5$ years of refereeing experience,

164 respectively. Self-efficacy data were collected in March 2020. Participants and Committee were

165 informed of the study procedures, objectives, methodology, benefits, and potential risks. This

166 study was approved by the Ethics Committee of the University of Granada (471/CEIH/2018).

Instruments

169 First, an socio-demographic ad-hoc test was established to collect data from each referee

170 corresponding to age, height, weight, refereeing experience, category, and injuries in the last 6

171 months. Second, the REFS (Referee Self-Efficacy Scale) questionnaire was administered in its

172 Spanish version (Guillén et al., 2019); it was initially developed by Myers et al. (2012) and

173 contains 13 items. It is a Likert scale of scoring from 1 to 5 , with 1 being very low confidence

174 and 5 being the highest confidence in their abilities. The questionnaire differentiates 4

175 dimensions: game knowledge (e.g., "Understand the basic strategy of the game", items 1-3),

176 decision making (e.g., "Make critical decisions during competition", items 4-6), pressure (e.g.,

177 "Uninfluenced by pressure from players", items 7-9) and communication (e.g., "Communicate

178 effectively with coaches", items 10-13). Regarding reliability, Cronbach's alpha coefficient in

179 terms of global self-efficacy was .883; in terms of constructs, reliability indexes between .745

180 and .794 were obtained, with pressure and communication being the lowest and highest indexes,

181 respectively (Table 1). To ensure the validity of the instrument, the questions and concepts to

182 Promote Transparent Reporting of Measurement Practices (Flake \& Fried, 2020) were taken into

183 consideration. The constructs have been defined and the theories that support them described in

184 the introduction. The selection of the measure has been justified, as well as the consideration of 
185 respecting the criteria for the administration procedure, the scores and the treatment, without 186 modifying any of the test questions.

\section{Design and Procedure}

189 This research was a descriptive cross-sectional study of a single sample collection. It took place

190 in March 2020, before the suspension of the competition by COVID-19 happened. Prior to this,

191 in September 2019, conversations were held with the Andalusian Committee of Football

192 Referees to accept that the study be carried out. A report was sent with the objectives,

193 instruments and actions carried out with the referees Later (in January 2020), and with the help

194 of these organizations, we contacted the SRs to explain the objectives, methodology, and

195 research protocols. In addition, each subject provided us written informed consent. Subsequently,

196 the questionnaire was sent to the SRs online so that they could complete it at home without any

197 influence from competition. Before completing the test, prior information was provided: e.g. the

198 name of the questionnaire, the scales being measured, and authors, among others. An email was

199 provided in case of doubt when completing the questionnaire. Regarding the inclusion criteria,

200 the referees belonged to the RFAF and had passed the corresponding physical tests to be able to

201 referee their category during the season. In addition, to be able to participate in the study, the

202 SRs must not have suffered serious injuries in the last 6 months that could affect them in the

203 development of the season. It should be noted that no SR who participated in the study received

204 any compensation. We gave the opportunity, to those who wished, to know the results of the 205 study after its publication.

206

207 Statistical analysis 
208 The SPSS 23.0 and AMOS 23.0 (IBM SPSS Statistic, Chicago, United States) programs were

209 used to carry out the statistical analysis. First, to check the normality of the sample, the

210 Kolmogorov-Smirnov test was carried out. Once the normal distribution of the sample was

211 verified, descriptive tests and $t$-test were performed for age as independent sample. To compare

212 different groups of experience and categories, one-way ANOVA test and subsequently a

213 Bonferroni post hoc correction were performed to determine differences between the groups. The

214 effect size in the ANOVA is presented by $\eta 2$ and was interpreted using the following criteria:

215 small effect $(\eta 2 \leq .02)$, moderate effect $(.02<\eta 2 \leq .09)$, and large effect $(\eta 2>.09)$ (Lakens, 2013).

216 The effect size for the $t$ test was interpreted with Cohen's d values. For interpretation of the effect

217 size, the following criteria were used: small effect $(d<.20)$, moderate effect $(.20 \leq d<.80)$, and

218 large effect ( $d \geq .80$ ) (O 'Donoghue, 2013). Likewise, a Pearson $r$ was performed to establish the

219 relationships between the different dimensions of the REFS questionnaire with age, category,

220 and seasons of experience of the SRs. The standards used for the classification of the correlation

221 coefficients, established by Hopkins (2000), were: trivial relationships $(r<.10)$, small $(.10<r$

$222<.30)$, moderate $(.30<r<.50)$, large $(.50<r<.70)$, very large $(.70<r<.90)$, almost perfect $(r>$

$223.90)$, or perfect $(r=1)$. Finally, a path analysis was performed to investigate the influence of

224 referee characteristics and self-efficacy dimensions (game knowledge, decision making, pressure,

225 and communication). To this end, the maximum likelihood method was selected with the

226 bootstrapping procedure with 5000 iterations considering the violation of multivariate normality

227 assumption (Mardia's coefficient $=4.168, p<.01)($ Kline, 2015). The goodness of fit was judged

228 with the following fit indexes: the rate $\chi^{2} /$ degrees of freedom $\left(\chi^{2} / d f\right)$, the Comparative Fit Index

229 (CFI), the Tucker-Lewis Index (TLI), the Standardised Root Mean Square Residual (SRMR), the

230 Root Mean Square Error of Approximation (RMSEA) with its confidence interval at 90\% (90\% 
231 CI), the Akaike Information Criterion (AIC), and the Bayes Information Criterion (BIC). The

232 rate $\chi 2 / d f$ is considered as an indicative of a good fit with values lower than 2 , the comparative

233 indexes (CFI and TLI) with values higher than 0.97, while the error of approximation indexes

234 with values lower than 0.05 for SRMR and RMSEA (Schermelleh-Engel et al., 2003). AIC and

235 BIC are typically used to compare the fit of competing models, where the model with the lowest

236 AIC and BIC values would represent the best-fit model (Kline, 2015).

237

238

239 Results

240 Table 1 shows the results of the normality and reliability tests. The evaluated dimensions show

241 medium-high reliability values. They present a normal distribution in all dimensions.

242

$243<$ Please insert table $1>$

245 Table 2 shows the means, standard deviations, level of significance, and size of the effect of the

246 following variables: knowledge of the game, decision making, pressure, communication, and

247 global self-efficacy in baseline states. To assess the existence of differences between groups,

248 Student's $t$-test was carried out for independent samples. Older SRs have higher levels in all

249 dimensions of self-efficacy when compared as a global variable $(p<.05)$ to the values of younger

250 SRs, with moderate effect sizes $(d)$.

251

$252<$ Please insert table 2> 
254 The differences obtained between the categories are shown in Table 3. Regarding game

255 knowledge, the SRs of the national category have the highest average; the values decrease across

256 category until they reach the base SRs. However, there are only significant differences between

257 the groups of national SR and base SR $(p<.05)$. Regarding decision making, the national

258 category had the highest values, and the values progressively decrease in lower categories; there

259 are significant differences between the national SRs with the provincial SR and base SR $(p<.05)$.

260 In the dimension of preassure, national SRs displayed a higher level of control than the base SRs.

261 There were significant differences between the national and base SRs $(p<.05)$ and between the

262 provincial SRs and base SRs $(p<.05)$. Regarding communication, the national SRs had a higher

263 mean value, but there were not significant differences between different groups. Finally, SRs of

264 higher category had higher mean global self-efficacy scores, and the scores decreased

265 progressively with significant differences in national SRs; there was also a significant difference

266 between Provincial and base SRs $(p<.05)$.

267

$268<$ Please insert table 3>

269

270 Table 4 shows the results of self-efficacy based on experience using the one-way ANOVA test.

271 For game knowledge, we observed a higher score in SRs with more experience in refereeing.

272 Significant differences were seen between the group of SRs with less experience and the

273 experienced and highly experienced SRs $(p<.05)$, but there was no difference between the

274 experienced and highly experienced SRs. The mean decision making progressive increased with

275 increasing experience in refereeing, and there were significant differences between SRs with less

276 experience and with the experienced and highly experienced SRs $(p<.05)$. However, between the 
277 experienced and highly experienced RH groups, no significant differences were observed. RP

278 follows the same pattern as the previous variables with a progressive increase as the SR acquires

279 more experience. There were significant differences between the less experienced SR group and

280 the experienced and very experienced SRs $(p<.05)$, but there was no difference between the

281 experienced and highly experienced SRs. There was an increase in the mean communication

282 score with increasing experience, with significant differences between the less experienced and

283 highly experienced RH groups $(p<.05)$. The global self-efficacy score increased as refereeing

284 experience increased. Likewise, significant differences were found between SRs with less

285 experience and the experienced and highly experienced SR $(p<.05)$.

286

$287<$ Please insert table $4>$

288

289 Table 5 shows the correlations of the REFS questionnaire variables with age, category, and years 290 of experience. All dimensions of self-efficacy have positive correlations with age, category, and

291 experience. The highest correlations were found in global self-efficacy, with coefficients ranging 292 from .35 and .42 . decision making had the second highest correlation with age and experience $(r$ $293=.32$ and $.38 ; p<.01 ;$ respectively).

$295<$ Please insert table 5>

297 Finally, multiple path analysis was performed in order to test the effect of intervening variables.

298 In figure 1, the path analysis of the influence of all the age, category and experience with

299 dimensions of self-efficacy can be observed. Table 6 presents the fit index obtained by the factor 
300 model. This model obtained a good fit to the observed data and the examination of standardized

301 regression weights revealed some characteristics in its internal structure for the model (see

302 Figure 1).

303

$304<$ Please insert table 6>

$305<$ Please insert figure 1 $>$

306 Figure 1. Standardized regression weights and error variances of each item for the factor model.

307 GK: Game knowledge; DM: Decision making; PR: Pressure; CO: Communication; CAT: Category.

$308 * p<.05 ; * * p<.01 ; * * *<<.001$.

309

310 Discussion

311 The aims of this study were to demonstrate that self-efficacy is greater in SR of higher category,

312 age and experience (measured as seasons as a referee), and to determine the relationship between

313 these variables. . All the analyses carried out have served to find variability in the self-efficacy of

314 a group as homogeneous as the referees. Specifically, in this study it is intended to know the

315 profile of self-efficacy that SRs have, so it is necessary to know in depth how the factors that

316 correspond to their characteristics affect. The results showed that SRs of higher category have a

317 higher level of self-efficacy, coinciding with a study carried out in handball referees (Diotaiuti et

318 al., 2017). In the game knowledge, the SRs of the National category obtained significantly higher

319 average scores compared to the other categories. This may be due to the domain of the

320 regulations and to the demanding theoretical tests Referee Committees require, which increase in

321 complexity across categories, adding to SRs' awareness of rules of the game (Ittenbach \& Eller,

322 1988). The National category SRs presented significantly higher scores in decision making than

323 the Provincial and Base SRs, possibly due to the strong relationship with game knowledge 
324 (Guillén et al., 2019; Myers et al., 2012). Increased game knowledge enables greater certainty in

325 decision making in competition, in the application of regulations, and in the swift translation of

326 judgement into actions (Helsen \& Bultynck, 2004; MacMahon et al., 2007). In communication

327 no differences were found between the categories, suggesting lack of a relationship (Table 5).

328 This may be because SRs are aware that effective communication is essential to maintain control

329 of the game (Grunska, 1999). Confidence and certainty in communicating both verbally and

330 nonverbally is emphasized starting in the base category. This may explain why there are no

331 differences between categories, in addition to the fact that in lower categories, the players are

332 small and the SRs progressively acquire and improve their language as the Committee gives

333 them confidence by assigning them higher category matches. Preassure is higher in national SRs,

334 since they have a greater impact in higher categories and should evolve along with psychological

335 skills. These findings support the hypothesis (H1a) that higher-category SRs have higher levels

336 of self-efficacy. Regarding age, older SRs had higher levels of self-efficacy, coinciding with the

337 recent study by Karacam and Adiguzel (2019) that used the same questionnaire (REFS) in

338 basketball referees; this study found moderate and even high positive relationships in variables

339 such as age. Our results differ from those of Nazarudin et al. (2014) in rugby referees; this study

340 found no significant differences between the same age groups. This may be explained by the

341 older age of the sampled referees, with only $25 \%$ of the sample being less than 30 years and with

342 a mean age of $33.4 \pm 1.5$ years. In addition, a study in SRs from the north of Spain found that

343 those over 40 years of age have greater stress control, which is positively related to self-efficacy

344 (Gonzalez-Oya \& Dosil, 2004). For these reasons, hypothesis H1b is supported.

345 High-experienced SRs had higher levels of self-efficacy, corroborated with large effect sizes and

346 agreement with results obtained by Diotaiuti et al. (2017). In addition, the correlation results are 
347 similar those of Karacam and Adiguzel (2019). However, they are much higher than those found

348 in the study by Karacam and Pulur (2017) in which small relationships were established $(0.1<\mathrm{r}<$

349 0.3) in the same dimensions of the REFS questionnaire with experience, in addition to age,

350 which could be due to the fact that the authors incorporated SR with basketball and handball

351 referees in the same analysis, hypothesizing that the requirements at psychological levels and

352 more specifically self-efficacy for each sport and, in categories of the sport itself, may not be the

353 same. Regarding decision making, SRs with less experience are perhaps more cautious when

354 making decisions since they have less control of the regulation and do not want to risk making a

355 wrong decision. This is supported by Myers et al. (2012), who found a positive relationship

356 between decision making and game knowledge (0.80). This may also be due to the lack of

357 communication skills in less experienced SRs who may show greater insecurity when addressing

358 players and coaches, added to a nonverbal language conveying SR insecurity to fans. RP

359 management is higher in SRs with more experience since their psychological skills are more

360 developed and they have lower levels of stress than those with less experience (González-Oya \&

361 Dosil 2004; Soriano et al., 2018). Communication dimension of SR self-efficacy evolves over

362 time and experience; at the beginning, it may be normal for SRs to not know how to address

363 technicians or players safely or to insecurity through nonverbal language to fans. However, as

364 observed, this aspect, like the others, evolves over years of experience. Finally, as in our study,

365 the increase in self-efficacy in terms of experience was also reflected in adolescents who

366 participated in an extracurricular sports activity program in the study by Reverdito et al. (2017)

367 where, through a linear regression, students with more than two years of experience obtained

368 greater benefits in terms of self-efficacy compared to those with less experience. Due to the

369 absence of findings on the relationship of self-efficacy and experience in the field of refereeing, 
370 we justify the results obtained in this study with those found in the adolescent population of the

371 study by Reverdito et al. (2017) as they are in line with our study. Therefore, we can confirm the

372 H1c and H2 hypotheses that high-experienced SRs have higher self-efficacy and that there are

373 moderate positive correlations between self-efficacy and the age, category, and experience of the

374 SRs, respectively.

375 Low levels of self-efficacy are related to greater stress and anxiety (Guillén et al., 2019), which

376 could cause burnout in SRs and trigger the abandonment of sports practice. In addition, optimal

377 self-efficacy could result in less impulsive decision making due to the absence or control of

378 stress over time and alleviation of negative influence on the perception of the environment, body,

379 time, cognition, and memory (Tornero-Aguilera et al., 2017). This would enable the SRs to

380 collect more information about each play and make better decisions. We consider self-efficacy to

381 be of great importance in SR performance, and according to Garcés de los Fayos and Vives

382 (2003), this has been scarcely studied. There are few psychological intervention programs in SR;

383 in Spain, there is one study (Ramírez et al., 2006) with the widely accepted implementation of

384 the PHIPA Program (“Intervention Program in Psychological Skills in Refereeing”). Currently,

385 in Spanish 3rd and 2nd B category referees the Talent and Mentors program mentioned in the SR

386 study by Fernández-Elías et al. (2017) focuses mainly on the aspects of sports performance and

387 regulations and their application. Considering the results of this study and others, SRs of lower

388 categories, ages, and experience who have lower levels of self-efficacy and probably other

389 psychological abilities could benefit from programs such as PHIPA or the of Talents and

390 Mentors to perfect refereeing from the base and develop skills as new SRs, thus preventing

391 burnout produced by verbal or physical aggressions that lead to abandonment of sports practice

392 (Alonso-Arbiol et al., 2005). 


\section{Limitations}

394 The present study shows different limitations. First, it is a cross section and the type of sampling

395 it presents is non-probabilistic. Second, the use of self-reported measures that may be subject to a

396 social desirability bias and that could influence the results. Another limiting factor can also be

397 the small number of the sample, although, it is representative of the amateur SR. Finally, it

398 would be necessary to include the physical condition values in order to establish the term level

399 within the factors that predict self-efficacy. Fitness tests are used to move up or down in

400 competition by causing a referee category. In this article, the category has been taken into

401 account, but there is a physical condition that could differ within the same category. For these

402 reasons, the term level in the referee could be very interesting for the future.

403 Future research should study the relationship between self-efficacy and impulsivity of SRs since

404 greater self-efficacy and less stress is correlated with improved perception of the environment

405 and judgment, which may influence confidence in impulsive decisions. These do not imply that

406 they are incorrect, but that they may take greater risks. This study could also be extrapolated to

407 other team sports (basketball, volleyball, and handball) in which the questionnaire can be used to

408 determine whether results are similar or for each sport and whether certain psychological skills

409 are required. Another possibility for future study could lie in conducting longitudinal cross-

410 sectional research with a Bayesian approach, assessing the evolution of SR self-efficacy during

411 the season at two or three different times, or even viewing over 2 or more seasons as the referee's

412 self-efficacy evolves. You could also compare and study the differences between professional

413 and amateur SRs and see if there are differences in terms of self-efficacy. As a final contribution

414 to future studies, control of stress or stress in SR could be evaluated together with self-efficacy in

415 order to establish relationships between stress and self-efficacy in SR. 


\section{Conclusions}

417 The main findings of the study show that self-efficacy of the amateur SR is conditioned by

418 category or level of the competition, age, and experience. These data open a line of research on

419 self-efficacy around SR due to the influence (determined by a large effect size) of SR

420 characteristics such as age, category and experience. The data obtained show the profile of the

421 amateur SR in terms of self-efficacy between different categories. In addition, this self-efficacy

422 could affect the decision-making and other decisive behaviors in the competition. In terms of

423 practical applications, they could help, understand and prevent burnout in lower-category SRs,

424 age and experience, at the same time that it could be a cause of why certain higher-category SRs

425 do not perform as well as in lower categories. Therefore, this study provides relevant information

426 for refereeing institutions, recommending promoting psychological intervention programs to

427 develop better psychological skills of newer, lower-category, and younger SRs to increase their

428 self-efficacy and their relationship with decision making as well as to prevent burnout and

429 abandonment of refereeing practice. 
430

431

432

433

434

435

436

437

438

439

440

441

442

443

444

445

446

447

448

449

450

451

\section{References}

Alonso-Arbiol, I., Falcó, F., López, M., Ordaz, B., \& Ramírez, A. (2005). Development of a questionnaire for the assessment of sources of stress in Spanish soccer referees. Ansiedad y Estrés, 11(2-3), 175-188.

Bandura, A. (1997). Self-efficacy: The exercise of control. New York: Freeman.

Barratt, E. S. (1994). Impulsiveness and aggression. In J. Monahan, \& H. J. Steadman (Eds.), Violence and mental disorder: Developments in risk assessment (pp. 61-79). Chicago: University of Chicago Press.

Barros, R. M. L., Misuta, M. S., Menezes, R. P., Figueroa, P. J., Moura, F. A., Cunha, S. A., Anido, R., \& Leite, N. J. (2007). Analysis of the distances covered by first division Brazilian soccer players obtained with an automatic tracking method. Journal of Sports Science and Medicine, 6, 233-242.

Bong, M. (2001). Between- and within-domain relations of academic motivation among middle and high school students: Self-efficacy, task value, and achievement goals. Journal of Educational Psychology, 93, 23-34.

Callan, V. J., Terry, D. J., \& Schweitzer, R. (1994). Coping resources, coping strategies and adjustment to organizational change: Direct or buffering effects? Work \& Stress: An International Journal of Work, Health \& Organisations, 8(4), 372-383. https://doi. org/10.1080/02678379408256543.

Di Salvo, V., Baron, R., Tschan, H., Calderon Montero, F. J., Bachl, N., \& Pigozzi, F. (2007). Performance characteristics according to playing position in elite soccer. International Journal of Sports Medicine, 28, 222-227. https://doi.org/10.1055/s-2006-924294 
452 Diotaiuti P., Falese L., Mancone S., \& Purromuto F. (2017). A Structural Model of Self Efficacy

453

454

455

456

457

458

459

460

461

462

463

464

465

466

467

468

469

470

471

472

473

in Handball Referees. Frontiers in Psychology, 8(811).

https://doi.org/10.3389/fpsyg.2017.00811

Ede, A., Hwang, S., \& Feltz, D. L. (2011). Current directions in self-efficacy research in sport. Revista Iberoamericana de Psicología del Ejercicio y el Deporte, 6(2), 181-201.

Federici, R. A., \& Skaalvik, E. M. (2012). Principal self-efficacy: Relations with burnout, job satisfaction and motivation to quit. Social Psychology of Education, 15(3), 295-320.

Fernández-Elías, V. E., Gómez-López, M. De la Vega, R., \& Clemente-Suárez, V. J. (2017). Physical demands, heart rate response and performance of talent football referees. Medicina dello Sport, 70(4), 447-456. https://doi.org/10.23736/S0025-7826.17.03076-9

FIFA (2004). Activity report: April 2002-March 2004. Fédération Internationale de Football Association. In: 54th Ordinary FIFA Congress. FIFA, ed. Paris, France: FIFA.

Flake, J. K., \& Fried, E. I. (2020). Measurement schmeasurement: Questionable measurement practices and how to avoid them. Advances in Methods and Practices in Psychological Science, 3(4), 456-465. https://doi.org/10.1177/2515245920952393

Garcés de los Fayos, E. J., \& Vives, L. (2003). Formación en árbitros y jueces deportivos: Mejora de las competencias y habilidades psicológicas del árbitro. En F. Guillén (Dir.), Psicología del arbitraje y el juicio deportivo (pp. 161-186). Barcelona: Inde.

González-Oya, J. (2006). Psicología aplicada al árbitro de fútbol: Características psicológicas y su entrenamiento. Sevilla: Wanceulen.

Giske, R., Hausen, T., \& Johansen, B. T. (2016). Training, mental preparation, and unmediated practice among soccer referees: An analysis of elite and sub-elite referees' reported 
474

475

476

477

478

479

480

481

482

483

484

485

486

487

488

489

490

491

492

493

494

495

practice. International Journal of Applied Sport Science, 28(1), 31-41. http://dx.doi.org/10.24985/ijass.2016.28.1.31

González-Oya, J. L., \& Dosil, J. (2004). Características psicológicas de los árbitros de fútbol de la Comunidad Autónoma Gallega. Cuadernos de Psicología del Deporte, 4(1-2), 53-66.

González-Oya, J., \& Dosil, J. (2007). La Psicología del árbitro de fútbol. Noia: Toxosoutos.

Guillén, F. (2003a). Características de eficacia requeridas en los árbitros y jueces deportivos [Effectiveness characteristics required from referees and sports judges]," in Psicología del Arbitraje y el Juicio Deportivo, ed. F. Guillén (Barcelona: Inde), 55-75.

Guillén, F. (2003b). Panorama actual en el estudio del arbitraje y el juicio deportivo desde una perspectiva psicológica, En F. Guillén (Dir.), Psicología del arbitraje y el juicio deportivo (pp. 7-24). Barcelona: Inde. Guillén, F., \& Feltz, D. L. (2011). A conceptual model of referee efficacy. Frontiers in Psychology, 2, 1-5. https://doi.org/10.3389/fpsyg.2011.00025

Guillén, F. Feltz, D., Gilson, T., \& Dithurbide, L. (2019). Analysis of the Psychometric Properties of the Spanish Version of Referee Self-Efficacy Scale (REFS). Revista de Psicología del Deporte, 28(1), 15-24.

Guillén, F., \& Jimenez, H. (2001). Características deseables en el arbitraje y el juicio deportivo. Revista de Psicología del Deporte 10, 23-34.

Grunska, J. (1999). Successful Sport Officiating. Champaign, IL: Human Kinetics.

Helsen, W., \& Bultynck, J. B. (2004). Physical and perceptual-cognitive demands of top-class refereeing in association football. Journal of Sports Sciences. 22, 179-189. https://doi.org/10.1080/02640410310001641502 
496 Hopkins, W. G. (2000). A new view of statistics. Internet Society for Sport Science:

497

498

499

500

501

502

503

504

505

506

507

508

509

510

511

512

513

514

515

516

517

\section{http://www.sportsci.org/resource/stats/}

Ittenbach, R. F., \& Eller, B. F. (1988). A personality profile of southeastern conference football officials. Journal of Sport Behavior. 11, 115-125.

Karacam, A., \& Adiguzel, N.S. (2019). Examining the Relationship between Referee Performance and Self-Efficacy. European Journal of Educational Research, 8(1), 377382. https://doi.org/10.12973/eu-jer.8.1.377

Karaçam, A., \& Pulur, A. (2017). Examining the relationship between referee self-efficacy and general self-efficacy levels of football, basketball and handball referees. Universal Journal of Educational Research, 5(9), 1571-1579. https://doi.org/10.13189/ujer.2017.050914

Kline, R. B. (2015). Principles and Practice of Structural Equation Modeling. Fourth ed. New York: The Guilford Press.

Lakens, D. (2013). Calculating and reporting effect sizes to facilitate cumulative science: A practical primer for t-tests and ANOVAs. Frontiers in Psychology, 4, 863. https://doi.org/10.3389/fpsyg.2013.00863

Loghmani, M., Taylor, T., \& Ramzaninejad, R. (2018). Job characteristics and psychological states of football referees: implications for job enrichment. Managing Sport and Leisure. 22(5), 342-357. https://doi.org/10.1080/23750472.2018.1426488

McCrae, R. R., Costa, P. T., de Lima, M. P., Simões, A., Ostendorf, F., Angleitner, A., Marušić, I., Bratko, D., Caprara, G. V., Barbaranelli, C., Chae, J.-H., \& Piedmont, R. L. (1999). Age differences in personality across the adult life span: Parallels in five 
cultures. Developmental Psychology, 35(2), 466-477. https://doi.org/10.1037/0012-

520 MacMahon, C., Helsen, W. F., Starkes, J. L., \& Weston, M. (2007). Decision-making skills and deliberate practice in elite association football referees. Journal of Sports Sciences. 25, 65-78. https://doi.org/10.1080/02640410600718640

523

Micoogullari, B. O., Gumusdag, H., Odek, U., \& Beyaz, O. (2017). Comparative study of sport mental toughness between soccer officials. Universal Journal of Educational Research, 5, 1970-1976. https://doi.org/10.13189/ujer.2017.051113

Muñoz-Arjona, C., \& Castillo-Rodríguez, A. (2020). Attitude vs. Aptitude. Effect of psychological responses on soccer referees. International Journal of Sport Psychology, 51(1), 69-80. https://doi.org/10.7352/IJSP.2020.51.069

Myers, N. D., Feltz, D. L., Guillén, F., \& Dithurbide, L. (2012). Development of, and initial validity evidence for, the Referee Self-Efficacy Scale: A multistudy report. Journal of Sport and Exercise Psychology, 34, 737-765. https://doi.org/10.1123/jsep.34.6.737

Nazarudin, M. N., Abdullah, M. R., Omar Fauzee, M. S., Abdullah, N. M., Noordin,H., \& Suppiah, P. K. (2014). Psychological skills assessment and referee rugby sevens performance. Journal for Educational Thinkers, 5, 165-184.

O’Donoghue, P. (2013). Statistics for sport and exercise studies: An introduction. New York: Routledge.

Ramírez, A., Alonso-Arbiol, I., Falcó, F., \& López, M. (2006). Programa de intervención psicológica con árbitros de fútbol. Revista de Psicología del Deporte, 15(2), 311-325.

Reverdito, R. S., Carvalho, H. M., Galatti, L. R., Scaglia, A. J., Gonçalves, C. E., \& Paes, R. R. (2017). Effects of Youth Participation in Extra-Curricular Sport Programs on Perceived 
541

542

543 Schweizer, G., Plessner, H., Kahlert, D., \& Brand, R. (2011). A video-based training method for 544 545

546

547

548

549

550

551

552

553

554

555

556

557

558

559

560

561

562

563

Self-Efficacy: A Multilevel Analysis. Perceptual and Motor Skills, 124(3), 569_ 583. doi:10.1177/0031512517697069 improving soccer referees' intuitive decision-making skills. Journal of Applied Sport Psychology, 23, 429-442. https://doi.org/10.1080/10413200.2011.555346

Soriano Gillué, G., Ramis Laloux, Y., Torregrossa Álvarez, M., \& Cruz i Feliu, J. (2018). Sources of Stress Inside and Outside the Match in Football Referees. Apunts. Educación Física y Deportes, 132, 22-31. https://doi.org/10.5672/apunts.20140983.es.(2018/2).132.02

Srivastava, S. J., John, O. P., Gosling, S. D., \& Potter, J. (2003). Development of personality in early middle adulthood: Set like plaster or persistent change? Journal of Personality and Social Psychology, 84, 1041-1053. https://doi.org/10.1037/0022-3514.84.5.1041

Stajkovic, A., \& Luthans, F. (1998). Self- efficacy and work-related performance: a metaanalysis. Psychol. Bull. 124, 240-261. doi: 10.1037/0033-2909.124.2.240

Sullivan, P. J., \& Kent, A. (2003). Coaching efficacy as a predictor of leadership style in intercollegiate athletics. Journal of Applied Sport Psychology, 15, 1-11.

Tornero-Aguilera, J. F., Robles-Pérez, J. J., \& Clemente-Suárez, V. (2017). Effect of combat stress in the psychophysiological response of elite and non-elite soldiers. The Journal of Medical Systems, 41(6), 100. https://doi.org/10.1007/s10916-017-0748-x.

Tornero-Aguilera, J. F., \& Clemente-Suárez, V. J. (2018). Effect of experience, equipment and fire actions in psychophysiological response and memory of soldiers in actual underground operations. International Journal of Psychophysiology, 128, 40-46. https://doi.org/10.1016/j.ijpsycho.2018.03.009 
564 Warner, S., Tingle, J., \& Kellett, P. (2013). Officiating attrition: The experiences of former

565 referees via a sport development lens. Journal of Sport Management, 27, 316-328.

$566 \quad$ http://doi.org/10.1123/jsm.27.4.316

567 Webb, T., Wagstaff, C. R. D., Rayner, M., \& Thelwell, R. (2016). Leading elite association

568 football referees: Challenges in the cross-cultural organization of a geographically

569 dispersed group. Managing Sport and Leisure, 21(3), 105-123.

$570 \quad$ DOI: $10.1080 / 23750472.2016 .1209978$

571 Weinberg, R. S., \& Richardson, P. A. (1990). Psychology of officiating. Champaign, IL: Leisure $572 \quad$ Press.

573 
Figure 1

Path Analysis with unstandardized coefficients between age, experience and category with self-efficacy dimensions.

GK: Game knowledge; DM: Decision making; PR: Pressure; CO: Communication; CAT:

Category.

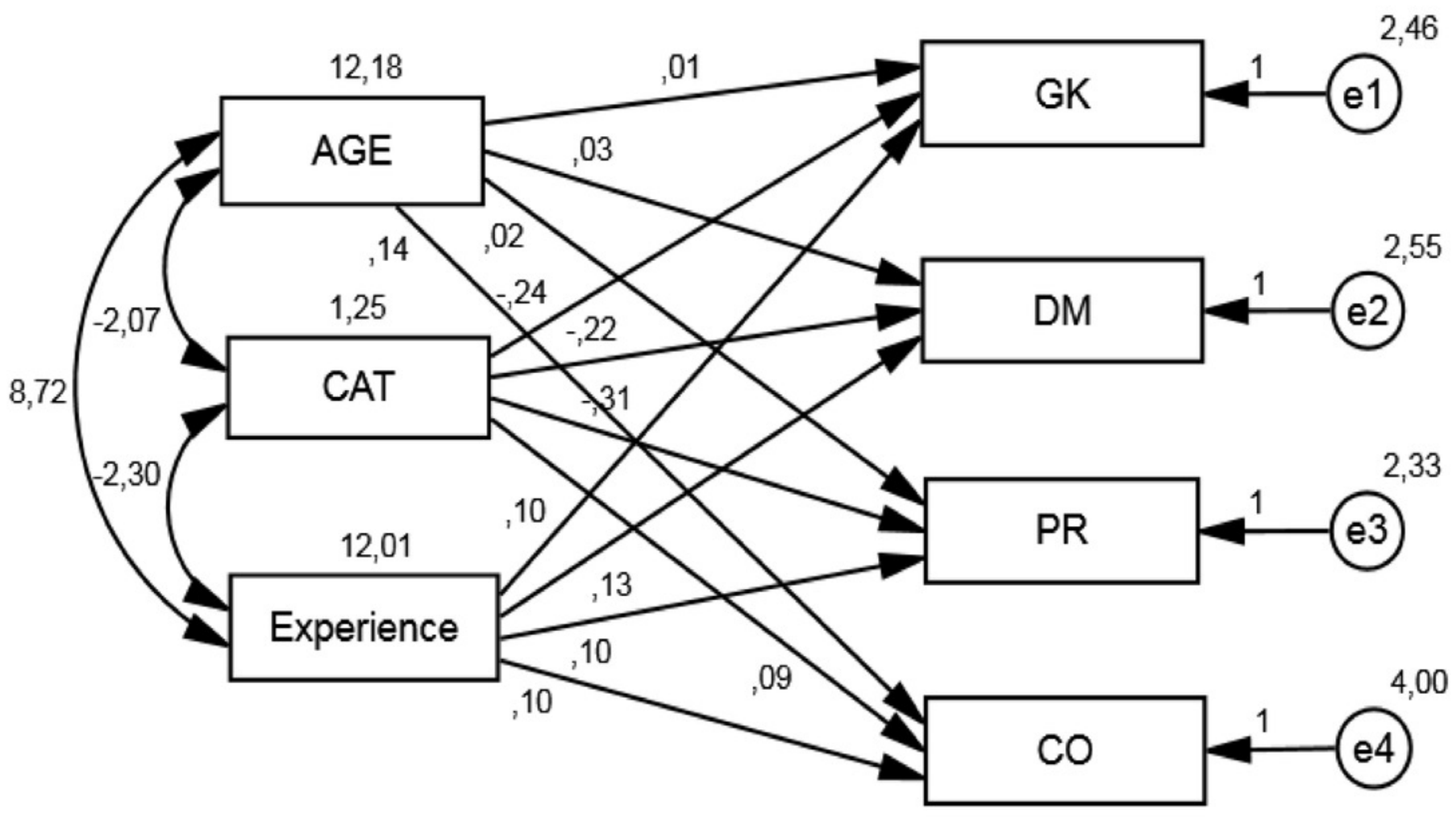




\section{Table $\mathbf{1}$ (on next page)}

Normality and reliability (Cronbach's $\alpha$ ) of the self-efficacy dimensions (REFS questionnaire).

${ }^{*} p \geq$.200; GK: Game knowledge; DM: Decision making; PR: Pressure; CO: Communication; $\Sigma$ Self-efficacy: Global self-efficacy. 
1 Table 1. Normality and reliability (Cronbach's $\alpha$ ) of the self-efficacy dimensions (REFS 2 questionnaire).

\begin{tabular}{ccc} 
& Normality & Reliability \\
\hline GK & $.053^{*}$ & .776 \\
DM & $.040^{*}$ & .794 \\
PR & $.088^{*}$ & .745 \\
CO & $.034^{*}$ & .766 \\
$\Sigma$ Self-efficacy & $.019^{*}$ & .883
\end{tabular}

$3{ }^{*} p \geq .200$; GK: Game knowledge; DM: Decision making; PR: Pressure; CO: Communication; $\Sigma$ Self-efficacy:

4 Global self-efficacy.

5 


\section{Table 2 (on next page)}

Comparison of Means of the Dimensions of Self-efficacy between SRs as a function of age.

GK: Game knowledge; DM: Decision making; PR: Pressure; CO: Communication; $\Sigma$ Selfefficacy: Global self-efficacy; Young SRs: from 18 to 24 years-old; Older SRs: from 25 to 34 years-old. Small effect (S) $(d<.20)$, moderate effect (M) $(.20 \leq d<.80)$, and large effect (L) $(d \geq .80)$ (O 'Donoghue, 2013). 
1 Table 2. Comparison of Means of the Dimensions of Self-efficacy between SRs as a function of 2 age.

\begin{tabular}{lccccccccccc}
\hline & \multicolumn{3}{c}{$\begin{array}{c}\text { Young SRs } \\
(\mathrm{n}=156)\end{array}$} & \multicolumn{4}{c}{$\begin{array}{c}\text { Older SRs } \\
(\mathrm{n}=100)\end{array}$} \\
\hline $\mathrm{GK}$ & 12.94 & \pm & 1.84 & 13.64 & \pm & 1.29 & .020 & .42 & $\mathrm{M}$ \\
$\mathrm{DM}$ & 12.56 & \pm & 1.78 & 13.70 & \pm & 1.46 & .000 & .68 & $\mathrm{M}$ \\
$\mathrm{PR}$ & 13.42 & \pm & 1.79 & 14.26 & \pm & 1.34 & .005 & .52 & $\mathrm{M}$ \\
$\mathrm{CO}$ & 16.77 & \pm & 2.08 & 18.08 & \pm & 1.97 & .001 & .64 & $\mathrm{M}$ \\
$\Sigma$ Self-efficacy & 55.69 & \pm & 5.60 & 59.68 & \pm & 5.17 & .000 & .73 & $\mathrm{M}$ \\
\hline
\end{tabular}

3 GK: Game knowledge; DM: Decision making; PR: Pressure; CO: Communication; $\Sigma$ Self-efficacy: Global self-

4 efficacy; Young SRs: from 18 to 24 years-old; Older SRs: from 25 to 34 years-old. Small effect (S) $(d<.20)$,

5 moderate effect (M) $(.20 \leq d<.80)$, and large effect (L) ( $d \geq .80)$ (O 'Donoghue, 2013). 


\section{Table 3 (on next page)}

Comparison of Means of the Dimensions of Self-efficacy between SRs according to the category.

GK: Game knowledge; DM: Decision making; PR: Pressure; CO: Communication; $\Sigma$ Selfefficacy: Global self-efficacy. Effect size in the ANOVA: small effect (S) ( $\eta 2 \leq .02)$, moderate effect (M) $(.02<\eta 2 \leq .09)$, and large effect (L) ( $\eta 2>.09)$ (Lakens, 2013). 
1 Table 3. Comparison of Means of the Dimensions of Self-efficacy between SRs according to the category.

\begin{tabular}{|c|c|c|c|c|c|c|c|c|c|c|c|c|c|c|c|c|}
\hline \multirow[b]{2}{*}{ GK } & \multicolumn{3}{|c|}{$\begin{array}{l}\text { National SRs } \\
\quad(n=72)\end{array}$} & \multicolumn{3}{|c|}{$\begin{array}{l}\text { State SRs } \\
(\mathrm{n}=50)\end{array}$} & \multicolumn{3}{|c|}{$\begin{array}{c}\text { Provincial SRs } \\
\qquad(\mathrm{n}=78)\end{array}$} & \multicolumn{3}{|c|}{$\begin{array}{c}\text { Base SRs } \\
(\mathrm{n}=56)\end{array}$} & \multirow{2}{*}{$\begin{array}{r}F(3,255) \\
\\
4.33\end{array}$} & \multirow{2}{*}{$\begin{array}{c}p \\
\\
.006\end{array}$} & \multicolumn{2}{|c|}{$\eta^{2}$} \\
\hline & 13.92 & \pm & $1.11^{4}$ & 13.16 & \pm & 1.43 & 13.13 & \pm & 1.45 & 12.46 & \pm & $2.37^{1}$ & & & .095 & $\mathrm{L}$ \\
\hline $\mathrm{DM}$ & 13.86 & \pm & $1.27^{3,4}$ & 12.96 & \pm & 1.43 & 12.77 & \pm & $1.91^{1}$ & 12.29 & \pm & $1.94^{1}$ & 5.15 & .002 & .111 & $\mathrm{~L}$ \\
\hline PR & 14.50 & \pm & $.94^{4}$ & 13.76 & \pm & 1.88 & 13.82 & \pm & $1.39^{4}$ & 12.68 & \pm & $2.06^{1,3}$ & 7.16 & .000 & .148 & $\mathrm{~L}$ \\
\hline $\mathrm{CO}$ & 17.97 & \pm & 1.91 & 16.96 & \pm & 2.03 & 17.05 & \pm & 2.04 & 17.00 & $=$ & 2.48 & 1.81 & .149 & .042 & M \\
\hline$\Sigma$ Self-efficacy & 60.25 & \pm & $3.71^{3,4}$ & 56.84 & \pm & 5.25 & 56.77 & \pm & $5.28^{1}$ & 54.43 & \pm & $7.32^{1}$ & 6.34 & .000 & .133 & $\mathrm{~L}$ \\
\hline
\end{tabular}

GK: Game knowledge; DM: Decision making; PR: Pressure; CO: Communication; $\Sigma$ Self-efficacy: Global self-efficacy.

Effect size in the ANOVA: small effect (S) $(\eta 2 \leq .02)$, moderate effect (M) $(.02<\eta 2 \leq .09)$, and large effect (L) ( $\eta 2>.09)$ (Lakens, 2013). 


\section{Table 4 (on next page)}

Mean comparisons of the self-efficacy dimensions between SRs based on experience.

GK: Game knowledge; DM: Decision making; PR: Pressure; CO: Communication; $\Sigma$ Selfefficacy: Global self-efficacy; Less-Experience SRs: 1-4 years/seasons; Experience SRs: 5-8 years/seasons; High-Experience SRs: $>8$ years/seasons. Effect size in the ANOVA: small effect (S) ( $\eta 2 \leq .02)$, moderate effect (M) $(.02<\eta 2 \leq .09)$, and large effect (L) ( $\eta 2>.09)$ (Lakens, 2013). 
1 Table 4. Mean comparisons of the self-efficacy dimensions between SRs based on experience.

\begin{tabular}{|c|c|c|c|c|c|c|c|c|c|c|c|c|c|}
\hline \multirow[b]{2}{*}{ GK } & \multicolumn{3}{|c|}{$\begin{array}{l}\text { Less-Experience SRs } \\
\qquad(\mathrm{n}=80)\end{array}$} & \multicolumn{3}{|c|}{$\begin{array}{l}\text { Experience SRs } \\
\qquad(\mathrm{n}=106)\end{array}$} & \multicolumn{3}{|c|}{$\begin{array}{l}\text { High-Experience SRs } \\
\qquad(\mathrm{n}=70)\end{array}$} & \multirow{2}{*}{$\begin{array}{c}F(2,255) \\
7.97\end{array}$} & \multirow{2}{*}{$\begin{array}{c}p \\
.001\end{array}$} & \multicolumn{2}{|c|}{$\eta^{2}$} \\
\hline & 12.40 & \pm & $2.10^{2,3}$ & 13.45 & \pm & $1.40^{1}$ & 13.77 & \pm & $1.14^{1}$ & & & .113 & $\mathrm{~L}$ \\
\hline DM & 12.05 & \pm & $1.87^{2,3}$ & 13.28 & \pm & $1.73^{1}$ & 13.69 & \pm & $1.11^{1}$ & 10.69 & .000 & .146 & $\mathrm{~L}$ \\
\hline PR & 13.00 & \pm & $1.95^{2,3}$ & 13.87 & \pm & $1.59^{1}$ & 14.43 & \pm & $1.04^{1}$ & 7.77 & .001 & .111 & $\mathrm{~L}$ \\
\hline $\mathrm{CO}$ & 16.48 & \pm & $2.28^{3}$ & 17.30 & \pm & 2.06 & 18.17 & \pm & $1.69^{1}$ & 6.46 & .002 & .094 & $\mathrm{~L}$ \\
\hline$\Sigma$ Self-efficacy & 53.93 & \pm & $6.49^{2,3}$ & 57.91 & \pm & $5.13^{1}$ & 60.06 & \pm & $3.68^{1}$ & 13.35 & .000 & .176 & $\mathrm{~L}$ \\
\hline
\end{tabular}

2 GK: Game knowledge; DM: Decision making; PR: Pressure; CO: Communication; $\Sigma$ Self-efficacy: Global self-efficacy; Less-Experience SRs: 1-4

3 years/seasons; Experience SRs: 5-8 years/seasons; High-Experience SRs: $>8$ years/seasons. Effect size in the ANOVA: small effect (S) $(\eta 2 \leq .02)$, moderate

4 effect (M) $(.02<\eta 2 \leq .09)$, and large effect (L) $(\eta 2>.09)$ (Lakens, 2013). 


\section{Table 5 (on next page)}

Correlation between Age, Category and years of experience with knowledge of the game, decision making, ability to withstand pressure, communication and onedimensional Self-efficacy.

GK: Game knowledge; DM: Decision making; PR: Pressure; CO: Communication; $\Sigma$ Selfefficacy: Global self-efficacy. ${ }^{*} p<0.01 ;{ }^{* *} p<0.001$. 
1 Table 5. Correlation between Age, Category and years of experience with knowledge of the 2 game, decision making, ability to withstand pressure, communication and one-dimensional Self3 efficacy.

\begin{tabular}{cccc}
\hline & Age & Category & Experience \\
\hline GK & $.255^{* *}$ & $.295^{* *}$ & $.314^{* *}$ \\
DM & $.315^{* *}$ & $.323^{* *}$ & $.382^{* *}$ \\
PR & $.303^{* *}$ & $.353^{* *}$ & $.364^{* *}$ \\
CO & $.313^{* *}$ & $.164^{*}$ & $.291^{* *}$ \\
$\Sigma$ Self-efficacy & $.374^{* *}$ & $.347^{* *}$ & $.421^{* *}$
\end{tabular}

4 GK: Game knowledge; DM: Decision making; PR: Pressure; CO: Communication; $\Sigma$ Self-efficacy: Global self-

5 efficacy. ${ }^{*} p<0.01 ;{ }^{* *} p<0.001$.

6 
Table 6(on next page)

Goodness-of-fit measures obtained in the factor model tested for the age, category and experience with multidimensional self-efficacy. 
1 Table 6. Goodness-of-fit measures obtained in the factor model tested for the age, category and

2 experience with multidimensional self-efficacy.

\begin{tabular}{cccccccc}
\hline$\chi^{2} / \mathrm{DF}$ & CFI & GFI & RMR & RMSEA & $\begin{array}{c}\text { RMSEA } \\
(90 \% \text { IC })\end{array}$ & AIC & BIC \\
\hline 2.914 & .936 & .941 & .040 & .048 & $.036-.054$ & 1958.40 & 1961.36 \\
\hline
\end{tabular}

3 